\title{
An issue of equity
}

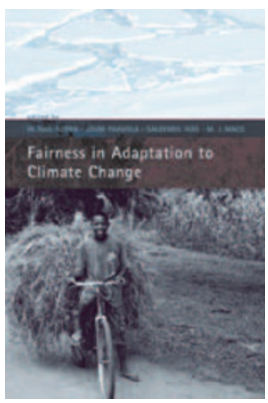

Gary Yohe

\section{The world's most vulnerable must be prioritized in adapting to climate change.}

\section{FAIRNESS IN ADAPTATION TO CLIMATE CHANGE}

\author{
Edited by W. Neil Adger, Jouni Paavola, Saleemul Huq and M. J. Mace
}

\section{MIT Press: 2006. 319 pp. $£ 16.95$}

It is well recognized that vulnerability to the impacts of climate change is unequal: the planet's poorest face the widest assortment of climate-related stresses and have the fewest tools to cope with them. In Asia, for example, 2.5 billion people live in rural areas on incomes of less than one dollar per day. They typically do not have access to sanitation, are vulnerable to disease and, coupled with illiteracy, poverty undermines their ability to pursue sustainable practices. The disaster-prone and ecologically fragile nature of their environment makes it unproductive, further increasing their exposure to climate risks. Similar demographics across Africa result in extreme exposure to the various manifestations of climate change that intensifies the pain of a vicious cycle of land degradation, polluted river catchments, desertification and diminished ecosystem services.

In an effort to explore what we know about the plight of the world's most vulnerable, Fairness in Adaptation to Climate Change brings together an extraordinary collection of scholarly essays that focus on the role of equity and fairness in supporting the capacity of human systems to adapt to climate change. It is a succinct presentation of the obvious - that access to resources is an essential prerequisite for adapting to any external stress - but it is also a careful discussion of the more subtle - that the capacity to adapt and equity are related through intricate webs of social, cultural, political and economic connections. These are prerequisites for effective adaptation that the world's poor are, for all intents and purposes, currently denied.

Because context can vary significantly from place to place, society to society and time to time, however, it is extremely difficult to tell an inclusive story about how equity and fairness should enter development plans and, perhaps more importantly, negotiations under the United Nations Framework Convention on Climate Change (UNFCCC). Equity issues are not foreign to the UNFCCC. We live in a world where the richest developed countries like the United States and the fasting growing emerging economies like China and India emit the largest proportion of greenhouse gases and developing nations suffer the largest proportion of negative impacts. The Convention asserts that this is, quite simply, not fair, and so countries that have signed the Convention have committed themselves to remedying the situation.

Several fundamental themes run through the entire collection, which is essentially a rigorous scholarly assessment of the role of equity in understanding adaptation. The first relates vulnerability to the social and environmental processes that limit the ability of systems to cope with climate-related stresses. Vulnerability is thereby appropriately and integrally related to the wider political economy within which it is located. The second theme argues that uncertainty (born of either imprecise understanding of climate change and sociopolitical-economic systems or conflicting norms of justice) is never a reason not to act. Some participants in the climate policy debate have used uncertainty to do just that; but this book provides more evidence that they are, quite simply, wrong in doing so.

A third holds that vulnerability must be measured using multiple "numeraires" or metrics. Here the essays are on the frontier of the academic discourse on impacts. Although many impacts can be expressed purely in economic terms, in other cases, different yardsticks must be recognized. For example, the Fourth Assessment Report of the Intergovenmental Panel on Climate Change makes no attempt to convert some of its major conclusions into economic measures. An additional $1{ }^{\circ} \mathrm{C}$ of warming would increase the number of people facing water scarcity by up to 1.2 billion additional people in Asia and 250 million in Africa and would cause as much as a $5 \%$ decline in wheat and maize productivity in India. Another degree of warming would cause China to experience a $12 \%$ decline in rice productivity, and water scarcity would affect an additional 1.6 billion people in Asia and Africa. These are risks that defy meaningful economic quantification, and they fall in places where most of the world's poor reside.

Two bookend chapters were crafted by the editors to tie these themes together with more than the usual signpost descriptions of who said what. The intervening chapters ask "So what?", and the somewhat academic discourse of the early chapters is brought to life in case studies from Bangladesh, Tanzania, Botswana, Namibia, Hungary and Vari.

The editors themselves then bravely tackle the more difficult question of "What do we do about it?". They argue that avoiding dangerous climate change is the minimum moral responsibility of the planet's most privileged decision-makers, but they also highlight that this is not simply a developeddeveloping country problem. Some of the world's most vulnerable people live in places like Darfur, but others are citizens of the wealthiest societies the planet has ever seen, in places like New Orleans. They argue correctly that allowing dangerous impacts would exacerbate inequity and other social problems everywhere, but they conclude optimistically that making progress towards reducing inequity across the globe and within individual communities could be good "climate policy".

To support their optimism, they offer a productive approach to adaptation, arguing persuasively for making the most vulnerable (wherever they live) the top priority in designing adaptation programs. All themes identified in the book can be found in the UNFCCC. All that remains is to weave them into meaningful implementation - the incredibly difficult task of asking the Parties of the UNFCCC to keep to their word.

Gary Yohe is Woodhouse/Sysco Professor of Economics at Wesleyan University, Connecticut, USA. e-mail:gyohe@wesleyan.edu 
Powerful position

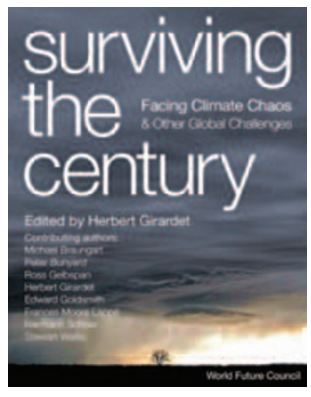

Chris Goodall

At its root, climate change is not a scientific or technical problem, but an issue of the use of power. SURVIVING THE CENTURY: FACING CLIMATE CHAOS AND OTHER GLOBAL CHALLENGES

\section{Edited by Herbert Girardet \\ Earthscan: 2007. 208 pp. $£ 17.99$}

A decade ago many involved in climate issues hoped it was a problem that the world would find relatively easy to conquer; the causes would be identified and mechanisms devised to reduce carbon emissions. With proper direction from a mixture of careful subsidies for low-carbon technologies and increased pollution taxes, the free market would eventually rein in our burgeoning greenhouse-gas emissions. But it hasn't turned out this way. Hopes of a strong and coordinated international approach have all but disappeared as most countries will fail to meet even the limited demands for emissions reductions imposed by the Kyoto Protocol.

Herbert Girardet's new book Surviving the Century: Facing Climate Chaos and Other Global Challenges brings together an eclectic mix of the initial optimists, from campaigning US journalist Ross Gelbspan to the German renewable energy pioneer Hermann Scheer. Containing a restrained but deeply felt passion, this book combines wisdom with an intense idealism about how mankind can make the radical changes necessary to deal with the issues that threaten our very existence.

At root, the authors argue, climate change is not a technical or scientific problem. The main impediment to tackling global warming is that many of the powerful institutions of the world, whether it be the World Trade Organization, BP or the investment banks that control the world's allocation of capital are resistant to radically changing the way we operate the world economy. The poor, whose share of world income is certainly not growing, are unable to successfully demand that policies be developed to protect them from climate change or from other environmental or economic disasters.

Large companies, the theory goes, are threatened by actions to reduce emissions. The oil and gas industry will suffer if the world moves to renewable energy. Monsanto's profits will fall if we switch from industrial agriculture back to lowinput farming methods. The Brazilian government will lose elections if it resists attempts to turn more of the rainforest into soy farms and cattle ranches. Freely operating markets, the book says, do not solve difficult problems. Markets concentrate power, rather than dispersing it, with the result that the success of global capitalism over the last twenty years has produced an elite of immense power and wealth. Aggressive action on climate change threatens this power, and is being resisted at every turn. The core thesis of the book, highlighted by Frances Moore Lappés analysis of the intertwining of democracy with free market economics, is that many of the world's most intractable problems are only solvable if we reduce the power of the global elite, whose influence is holding back any attempt to restructure the world's economic system.

But, rather than being merely a diatribe against the institutions of corrupted global capitalism, this is a far more nuanced and hopeful work. Most of the discussion is given over to proposals for substantial actions to remedy the world's bias towards using fossil fuels. Michael Braungart looks at how industrial processes can be re-engineered with fairness and ecological awareness. He points out that the most productive and efficient economies, judged in the conventional sense, are often the most wasteful and destructive. Herbert Girardet extols the virtues of the first city to be built with environmental issues firmly in mind.
It is nevertheless worth pointing out that the world's first eco-city, in Dongtan, East Asia still has an ecological footprint larger than can be sustained, and is but one of a huge number of new urban centres rising across China.

Of the eight excellent essays in this book, I think the one that should most attract our attention is Paul Bunyan's work on the Amazon rainforest. Even those who know little about global warming are becoming dimly aware of the role of this enormous area on the world's climate. International treaties, including Kyoto, have failed to recognize the importance of tropical forests both as carbon sinks and as stabilizers of our weather systems. The maintenance of the forest depends on high rainfall, which largely comes from the evapotranspiration of rainfall elsewhere in the forest. Deforestation may cause diminished rainfall and eventual disruption of the Hadley cell circulation, changing the world's climate system in potentially catastrophic ways. And deforestation is, to reprise the core theme of this book, carried out "by just a handful of Brazilians" eager to use the land for soy and cattle. This elite, and other similar groups across the world, hold the world's fate in their hands.

But the reader cannot take much comfort from this book: the chances of its sensible recommendations being adopted by those in authority are low. Progress at weaning the world off its reliance on fossil fuels will continue to be blocked by those who benefit from the persistent underpricing of carbon.

Chris Goodall is the author of How to Live a Low-Carbon Life: The Individual's Guide to Stopping Climate Change.

e-mail:c.goodall@which.net 


\title{
A challenge to Kyoto
}

\author{
Partha Dasgupta
}

\section{Standard cost-benefit analysis may not apply to the economics of climate change.}

\section{COOL IT: THE SKEPTICAL ENVIRONMENTALIST'S GUIDE TO GLOBAL WARMING}

\section{by Bjorn Lomborg \\ Knopf/Cyan-Marshall Cavendish: 2007. 272 pp./256 pp. \$21/E19.99}

\section{Bjorn Lomborg's The Skeptical} Environmentalist created a sensation six years ago. The author offered figures to dismiss claims that the ecologicalresource base in many parts of the world is deteriorating, and argued that the costs of reducing ecological losses are usually higher than the benefits. Never mind that several of the world's foremost environmental scientists expressed more than mere scepticism towards Lomborg's grasp of their science: prominent publications such as The Economist promoted the book vigorously and wrote sermons on how scientists should practise their craft. People learning of my own work in developing ecological economics would ask, "And have you read Lomborg?" — implying, "Why have you thrown away so much of your working life?"

Things have changed over the past year. Former US vice-president Al Gore's film An Inconvenient Truth and the Fourth Report of the Intergovernmental Panel on Climate Change have given rise to great public concern, and many now regard global warming to be the central problem facing humanity. Lomborg's latest book, Cool It, is a response to that change in public perception. He doesn't question the science, which says that rising concentrations of greenhouse gases in Earth's atmosphere are affecting our climate system; he questions whether we should do much about it. If The Skeptical Environmentalist was the relentless prosecuting counsel, Cool It is the hardheaded but caring economist.

The book is a series of exercises in cost-benefit analysis, interspersed with quotes on climate change from the writings of famous people who should know better than to speak in hyperboles. Lomborg produces figures to show that it would be better to replace the Kyoto Protocol with strategies that encourage economic growth and blunt the harmful effects of

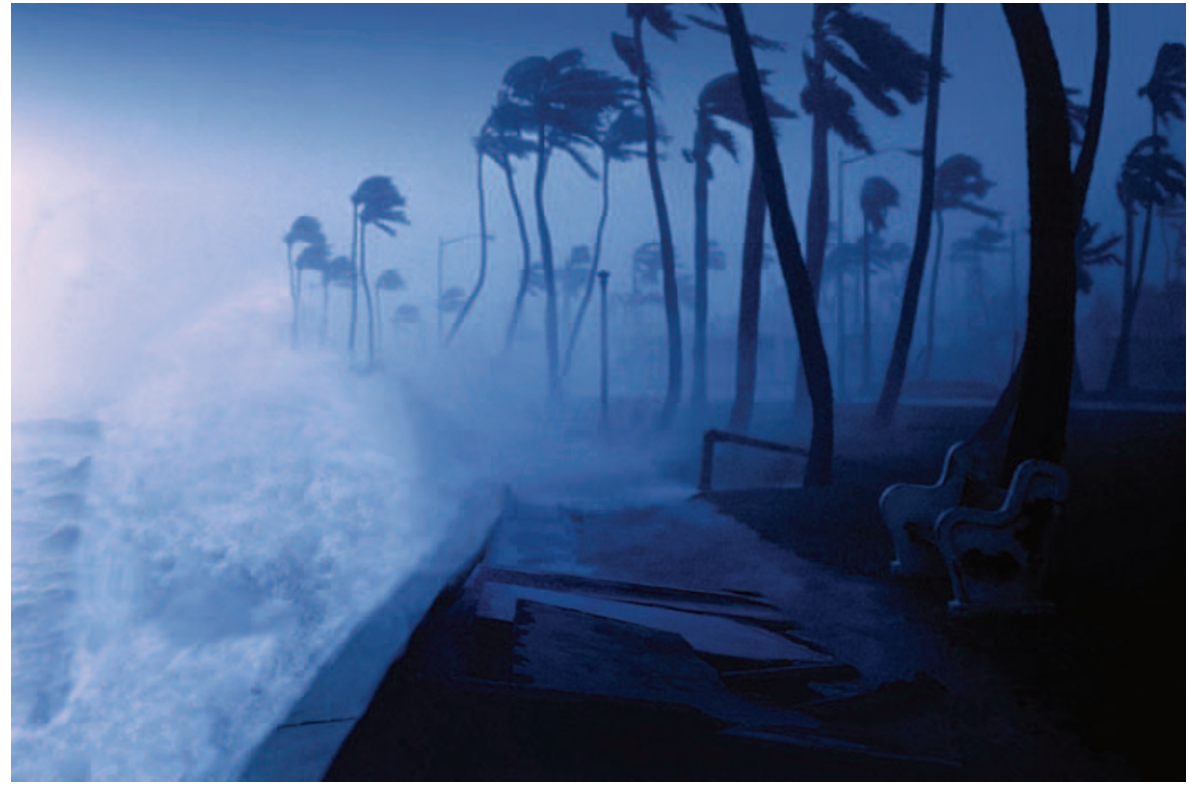

Should we be spending more on protecting ourselves against the adverse effects of global warming?

climate change. Here is a sample: did you say Kyoto would result in fewer floods? Maybe, but it would reduce flood damage by only US $\$ 45$ million a year, whereas building appropriate infrastructure could lower it by $\$ 60$ billion a year. Didn't you also say that global warming would cause additional deaths from heatwaves? Yes, but what about the greater numbers who would not die of cold? Are you worried about deepening poverty in the tropics without Kyoto? You shouldn't be, because Kyoto would reduce the number of undernourished people in 2080 by only 2 million, whereas the United Nations proposes in its Millennium Development Goals to reduce the number by 229 million by 2015 . What about more severe hurricanes? Well, Kyoto would reduce the increased annual damage by only $0.6 \%$, whereas taking better precautions could lower it by $250 \%$. And so on.
Lomborg reports that Kyoto's annual cost would be $\$ 180$ billion in foregone output, whereas the smart strategies he outlines, which would include an annual expenditure of $\$ 25$ billion on research and development in clean technologies, would cost a mere $\$ 52$ billion a year. By his reckoning, those strategies would limit the rise in concentration of carbon dioxide to 560 parts per million (p.p.m.) and the accompanying temperature rise to $4.7^{\circ} \mathrm{C}$. Smart strategies would cost far less than Kyoto, deliver higher economic growth worldwide, and markedly reduce poverty. From the vantage point of Kyoto, there is a free lunch to be had wherever you look.

You might say that the Kyoto Protocol was misconceived and that the world should develop a bolder programme of action, with much higher carbon taxes, international cooperation to reduce hunger, disease and habitat destruction, 
and development of clean technologies and ways to sequester carbon. But in Lomborg's view, doing more of a bad deal is rarely smart, so he doesn't countenance going beyond Kyoto. All this is spelt out in such a breezy, engaging style, it's hard not to find the arguments entirely reasonable.

Unfortunately, Lomborg's thesis is built on a deep misconception of Earth's system and of economics when applied to that system. The concentration of $\mathrm{CO}_{2}$ in the atmosphere is now 380 p.p.m., a figure that ice cores in Antarctica have revealed to be in excess of the maximum reached during the past 600,000 years. If there is one truth about Earth we all should know, it's that the system is driven by interlocking, nonlinear processes running at different speeds. The transition to Lomborg's recommended concentration of 560 p.p.m. would involve crossing an unknown number of tipping points (or separatrices) in the global climate system. We have no data on the consequences if Earth were to cross those tipping points. They could be good, or they could be disastrous. Even if we did have data, they would probably be of little value because nature's processes are irreversible. One implication of the Earth system's deep nonlinearities is that estimates of climatic parameters based on observations from the recent past are unreliable for making forecasts about the state of the world at $\mathrm{CO}_{2}$ concentrations of 560 p.p.m. or higher. Moreover, the nonlinearities mean that doing more of a bad deal (Kyoto) may well be very good.

These truths seem to escape Lomborg. His cost-benefit analysis involves only point estimates of variables (interpreted variously as 'most likely', 'expected', and so forth), implying that he believes we shouldn't buy insurance against potentially enormous losses resulting from climate change. His concerns over the prevalence of malaria, undernutrition and HIV in today's world show that he is an egalitarian. There is, then, an internal contradiction in his value system, because if you are averse to inequality you should also be averse to uncertainty.

The integrated assessment models of Earth's system on which Lomborg builds his case are arbitrarily bounded on either side of his point estimates. It can be shown that if those bounds are removed (as they ought to be), even a small amount of uncertainty - when allied to only a moderate aversion to uncertainty - would imply that humanity should spend substantial amounts on insurance, even more than the $1-2 \%$ of world output that has been advocated. If the uncertainties are not small, standard cost-benefit analysis as applied to the economics of climate change becomes incoherent, even if those uncertainties are judged to be thin-tailed (gaussian, for example); this is because the analysis would say that no matter how much humanity chooses to invest in protecting Earth from passing through those later tipping points, we should invest still more.

Economics helps us to realize what we are able to say about matters that will reveal themselves only in the distant future. Simultaneously, it helps us to realize the limits of what we are able to say. That, too, is worth knowing, for limits on what we are able to say are not a reason for inaction. Lomborg's seemingly persuasive economic calculations are a case of muddled concreteness.

Partha Dasgupta is professor of economics at the University of Cambridge and fellow of St John's College, Cambridge. He is author of Discounting Climate Change, forthcoming in Review of Environmental Economics and Policy.

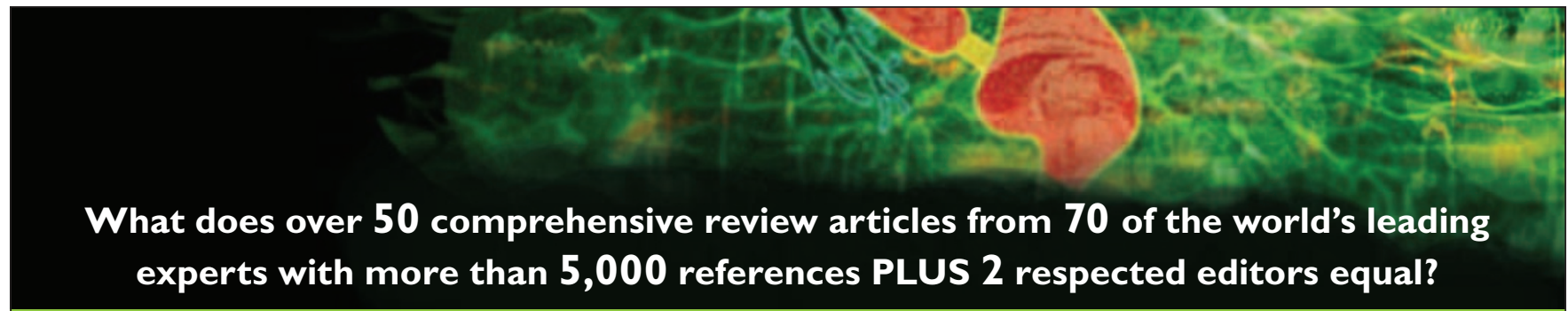

\title{
Goyal \& Shaker G Motility
}

\author{
A FREE website for clinicians and researchers interested in \\ gastrointestinal motility.
} www.gimotilityonline.com

Now available: PART I Oral cavity, pharynx and esophagus

GI Motility online is a unique, comprehensive resource on the motility of the gastrointestinal tract. Edited by Raj Goyal, M.D. and Reza Shaker, M.D., and with contributions from leading international experts, GI Motility online provides in-depth review articles, easily-assimilable overviews, case studies for self-learning, and 'How To' carry out important motility investigations.

- Over $\mathbf{5 0}$ comprehensive review articles from leading contributors

- Video clips, images and tables enhance the text

- Links to over 5,000 reference to the world's literature
- Reference material for quick overview

- Instructional videos on key examination techniques

- Case studies for self learning
Dr Raj K. Goyal is Mallinckrodt Professor of Medicine, Harvard Medical School and staff physician at the VA Boston Healthcare System (VABHS). He earned his M.B. B.S. from Amritsar Medical College, Panjab University, and his M.D. from Maulana Azad Medical College, University of Delhi, in India.
Dr Reza Shaker is Professor of Medicine, Radiology, and Otolaryngology, Chief of the Division of Gastroenterology and Hepatology, and Directo of the Digestive Disease Center at the Medical College of Wisconsin - Milwaukee, WI. 